\title{
Autologous Cultured Acute Myeloid Leukemia-specific Cytotoxic T Lymphocytes
}

National Cancer Institute

\section{Source}

National Cancer Institute. Autologous Cultured Acute Myeloid Leukemia-specific

Cytotoxic T Lymphocytes. NCI Thesaurus. Code C111996.

A preparation of cytotoxic, autologous acute myelogenous leukemia (AML)-reactive $T$ lymphocytes (CTL), with potential immunomodulating and antineoplastic activities. The autologous cultured AML-specific CT Ls are prepared using a specific AML-CTL culture method. Autologous peripheral blood lymphocytes are taken from an AML patient and the autologous AML blasts are treated with granulocyte macrophage colony-stimulating factor (GM-CSF) and interleukin 4 (IL-4), both of which promote ex vivo differentiation of AML blasts into dendritic cells (DCs). In the same culture, T cells are treated and activated by low-dose interleukin 2 (IL-2), and expanded using anti-CD3. This results in cultured AML-reactive CT Ls which are administered back into the patient after autologous hematopoietic stem cell transplant (AHSCT). The autologous cultured AML-specific CTLS may eradicate residual $A M L$ cells. 